\title{
Ácidos orgânicos na qualidade fisiológica de sementes de arroz
}

\author{
Effect of organic acids in physiological quality of rice
}

\author{
Lilian Madruga de Tunes ${ }^{\mathrm{I}}$ Lizandro Ciciliano Tavares ${ }^{\mathrm{II}}$ Géri Eduardo Meneghello ${ }^{\mathrm{II}}$ \\ Daniel Ândrei Robe FonsecaII Antonio Carlos Souza Albuquerque Barros ${ }^{\mathrm{II}}$ \\ Cassyo de Araújo Rufino II
}

\section{RESUMO}

\begin{abstract}
O alagamento do solo para o cultivo do arroz irrigado promove condições anaeróbias que favorecem a produção de ácidos orgânicos de cadeia curta, os quais podem ser tóxicos para a cultura. No presente trabalho, o objetivo foi avaliar a qualidade fisiológica de sementes de arroz irrigado cultivar 'IRGA 424', submetidas ao estresse por diferentes ácidos orgânicos, sendo selecionados aqueles formados no solo: acético, propiônico e butírico, utilizando-se as doses de 0, 4, 8, 12 e 16mM, nas quais as sementes foram embebidas por um período de 90 minutos $e$ em seguida submetidas a testes de germinação e vigor (primeira contagem da germinação, comprimento e massa seca da parte aérea e raízes). Na avaliação da qualidade das sementes frente ao estresse por ácidos orgânicos, o comprimento das raízes foi mais eficiente para diferenciar a toxicidade nas doses de ácido acético, butírico e propiônico. O ácido butírico foi o mais prejudicial para sementes de arroz, afetando o desenvolvimento inicial das plântulas da cultivar 'IRGA 424'.
\end{abstract}

Palavras-chave: Oryza sativa L., ácido acético, ácido propiônico, ácido butírico, germinação, vigor.

\section{ABSTRACT}

Flooding the soil for rice cultivation promotes anaerobic conditions that favor the production of short-chain organic acids, which can be toxic to the culture. This study aimed to evaluate the physiological quality of seeds of rice cultivar 'IRGA 424' subjected to stress by different organic acids. We studied three organic acids formed in the ground and five levels, namely: acetic, propionic, and butyric acid in doses 0, 4, 8, 12 and 16mM. The seeds were soaked in solutions and in the doses above, for a period of 90 minutes, after, were tested for germination and vigor (first count germination, shoot length and root and shoot dry mass and root). In evaluating the quality of the seed facing the stress by organic acids, the variable length of the roots was the most efficient to differentiate the toxicity by different doses of acetic acid, propionic and butyric. The butyric acid was the most damaging to rice seeds, affecting early development of seedlings of the cultivar 'IRGA 424'.

Key words: Oryza sativa L., acetic acid, propionic acid, butyric acid, germination, vigor.

\section{INTRODUÇÃo}

A característica principal da cultura do arroz irrigado é a manutenção de uma lâmina de água sobre o solo durante a maior parte de seu desenvolvimento, de forma que o oxigênio $\left(\mathrm{O}_{2}\right)$ presente no solo é consumido e os microorganismos anaeróbicos passam a atuar produzindo elevada quantidade de produtos intermediários fitotóxicos, por meio da fermentação da matéria orgânica presente (KOPP et al., 2008).

Os principais produtos fitotóxicos produzidos são os ácidos orgânicos alifáticos de baixo peso molecular (acético, propiônico e butírico), que ocorrem na faixa de concentração de 0,1 a 16mM (ANGELES et al., 2005) e relação de 6:3:1, respectivamente (BOHNEN et al., 2005), os quais atingem valor máximo poucos dias após o alagamento, podendo ocorrer toxidez às plantas (SOUSA \& BORTOLON, 2006).

A toxidez por ácidos orgânicos é manifestada, principalmente, no início do desenvolvimento do arroz, sendo caracterizado por uma menor germinação, crescimento inicial

'Departamento de Defesa Fitossanitária, Universidade Federal de Santa Maria (UFSM), 97105-900, Santa Maria, RS, Brasil. Email: lilianmtunes@yahoo.com.br. Autor para correspondência.

"Departamento de Fitotecnia, Universidade Federal de Pelotas (UFPel), Pelotas, RS, Brasil. 
lento, menores crescimento radicular, absorção de nutrientes e rendimentos de grãos (BORTOLON et al., 2009). Assim, ainda segundo os autores, a adoção de sistemas de cultivo com uma maior perspectiva de aporte de material orgânico via rotação de culturas e a manutenção de resíduos vegetais na superfície do solo provocam aumento da produção dos ácidos.

Uma das alternativas para minimizar os prejuízos causados pela toxidez dos ácidos orgânicos seria a utilização de cultivares de arroz tolerantes (KOPP et al., 2007a), no entanto, as informações são escassas a respeito da tolerância de cultivares de arroz irrigado recomendadas para o Rio Grande do Sul. Diante dessas considerações, o objetivo neste trabalho foi avaliar a qualidade fisiológica de sementes de arroz irrigado, cultivar 'IRGA 424' submetidas ao estresse por diferentes ácidos orgânicos.

\section{MATERIAL E MÉTODOS}

Os três principais ácidos orgânicos avaliados foram: acético, propiônico e butírico, em cinco doses $(0,4,8,12$ e $16 \mathrm{mM})$, cujas sementes foram embebidas nas soluções com as respectivas concentrações por um período de 90 minutos e, em seguida, retiradas e colocadas em papel toalha durante três horas (NEVES \& MORAES, 2005).

Para avaliação do efeito das doses dos ácidos, conduziram-se os seguintes testes: Germinação (G): utilizando-se quatro subamostras de 100 sementes, as quais foram distribuídas sobre duas folhas de papel toalha tipo germitest, cobertas com uma terceira e organizadas em forma de rolo. O papel toalha foi umedecido com água destilada e esterilizada, na quantidade equivalente a 2,5 vezes a sua massa seca. Os rolos foram mantidos em germinador à temperatura constante de $25^{\circ} \mathrm{C}$, cujas contagens foram realizadas aos 14 dias após a semeadura, segundo os critérios estabelecidos pelas Regras para Análise de Sementes (BRASIL, 2009) e os resultados expressos em porcentagem de plântulas normais. Primeira contagem de germinação (PCG): realizada conjuntamente com o teste de germinação, com contagem realizada aos cinco dias após a semeadura, sendo os valores expressos em porcentagem de plântulas normais (BRASIL, 2009). Comprimento da parte aérea (CPA) e raiz (CR): avaliou-se o comprimento médio de 10 plântulas normais, aleatoriamente, obtidas a partir da semeadura de quatro repetições de 20 sementes por tratamento, no terço superior da folha de papel toalha umedecida com água destilada e esterilizada, na quantidade equivalente a 2,5 vezes a sua massa seca. Os rolos de papel contendo as sementes permaneceram por cinco dias em germinador regulado à temperatura constante de $25^{\circ} \mathrm{C}$; em seguida, avaliou-se o comprimento da parte aérea e raiz com auxílio de uma régua graduada em milímetros. O comprimento da parte aérea e raiz foi obtido somando-se as medidas de cada repetição por tratamento e dividindo-se pelo número de plântulas normais, cujos resultados foram expressos em centímetros (KRYZANOWSKI et al., 1999). Massa seca de raízes (MSR): as plântulas foram seccionadas, separando-se o sistema radicular da parte aérea e, em seguida, foram colocadas separadas em cápsulas de alumínio, mantidas em estufa com convecção de ar regulada a $64^{\circ} \mathrm{C}$ durante $72 \mathrm{~h}$. Posteriormente, foi avaliada a massa seca da parte aérea e das raízes utilizando-se uma balança analítica de precisão $(0,0001 \mathrm{mg})$ e os resultados expressos em g plântula ${ }^{-1}$ (BRASIL, 2009).

O delineamento experimental foi inteiramente ao acaso, com os tratamentos distribuídos em esquema fatorial 3x5 (ácidos orgânicos e doses); os dados obtidos foram submetidos à análise de variância, sendo as médias comparadas pelo teste de Tukey $(\mathrm{P}>0,05)$, utilizando o programa de análises estatísticas Sisvar (FERREIRA, 2000); também foi realizada análise de regressão polinomial.

\section{RESULTADOS E DISCUSSÃO}

As concentrações dos ácidos orgânicos foram selecionadas a partir de estudos anteriores, pelos quais concluiu-se que a sua fitotoxide aumentou na seguinte ordem: ácido acético, propiônico e butírico, pois, quanto maior a cadeia carbônica, mais tóxico será (BORTOLON et al., 2009).

Pelos dados de germinação e vigor (primeira contagem de germinação e comprimento da parte aérea), verificou-se que as doses de 4, 8 e $12 \mathrm{mM}$ diferiram apenas no ácido butírico, sendo que este ocasionou uma redução na qualidade das sementes e a dose de $16 \mathrm{mM}$ foi mais prejudicial às sementes na seguinte ordem: ácido acético, propiônico e butírico. Para o comprimento da parte aérea (CPA), o ácido propiônico foi o menos danoso ao desenvolvimento das plântulas na dose de $16 \mathrm{mM}$ (Tabela 1) e o ácido butírico causou maiores problemas a partir da dose de $4 \mathrm{mM}$, contrariando os dados obtidos por CAMARGO et al. (1993), que também trabalharam com sementes de arroz irrigado.

Ainda, pelos dados da tabela 1 , constatouse que houve variação e redução no comprimento das raízes (CR) das plântulas de arroz da cultivar 'IRGA 424', quando comparados os ácidos orgânicos; assim 
Tabela 1 - Germinação (G), primeira contagem da germinação (PCG), comprimento de parte aérea (CPA), raízes (CR) e massa seca de raízes de plântulas de arroz da cultivar 'IRGA 424', em função de diferentes doses de ácidos orgânicos.

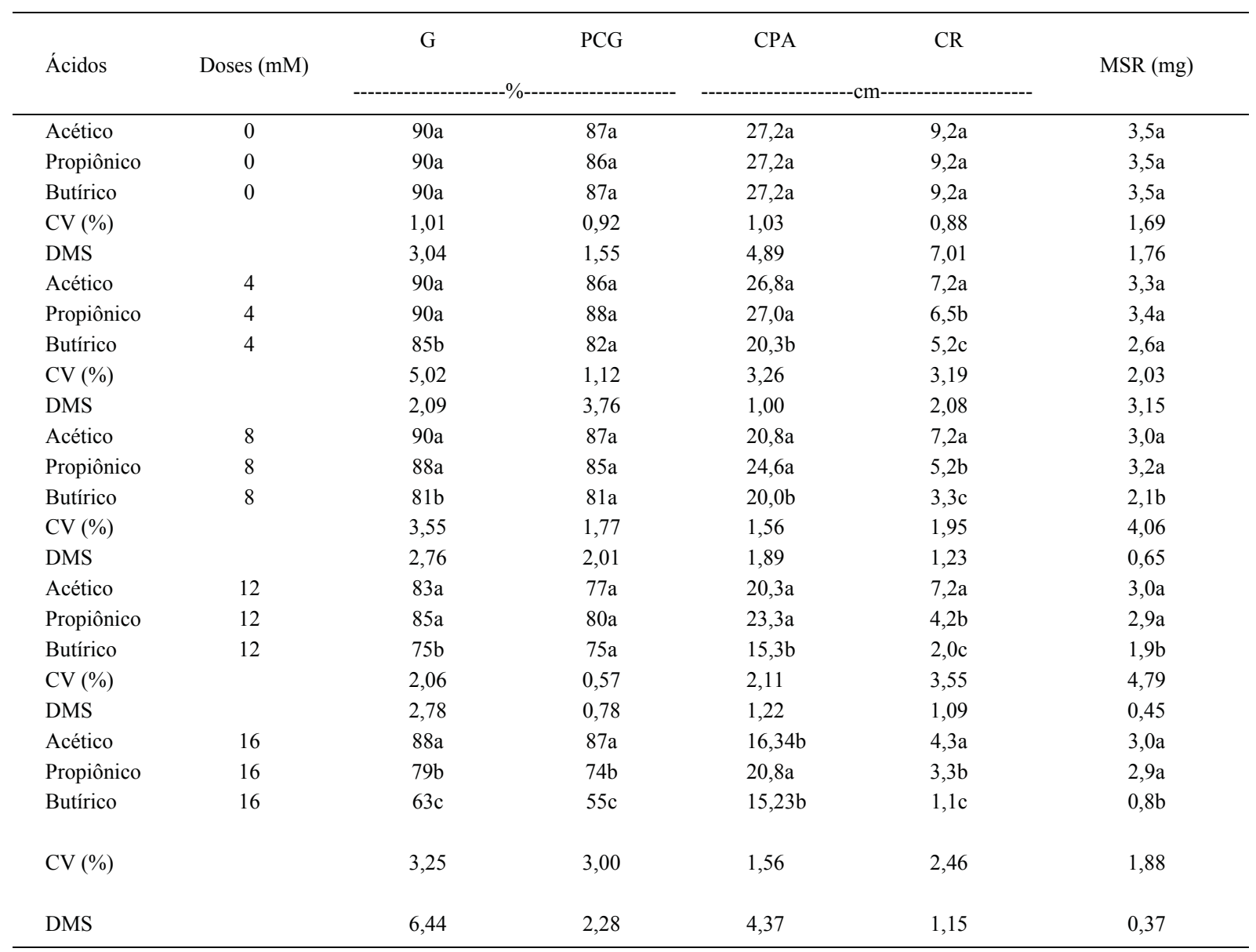

*Médias seguidas pela mesma letra minúscula na coluna, em cada variável, não diferem entre si pelo teste de Tukey (P>0,05).

o ácido butírico, em todas as doses avaliadas, foi o que mais prejudicou o desenvolvimento radicular, concordando com TAKENAGA (1995), quando observou que a fitotoxidez dos ácidos orgânicos decorre da diminuição da respiração e fosforilação oxidativa do sistema radicular. Segundo pesquisa de NEVES et al. (2010), os ácidos orgânicos são inibidores de funções da mitocôndria, ocasionando o desacoplamento da fosforilação oxidativa, transporte de metabólicos de enzimas glicolíticas solúveis no citossol e funções ligadas a membranas, em que as mais afetadas são a síntese de polissacarídeos e a ATPase, comprometendo todo o desenvolvimento da planta.

A massa seca de raízes (MSR) também diferiu entre os ácidos analisados (Tabela 1), sendo mais prejudicada pelo ácido butírico nas doses 8, 12 e $16 \mathrm{mM}$. Resultados semelhantes foram obtidos por NEVES e MORAES (2005) quando submeteram sementes de arroz irrigado da cultivar 'Epagri 111' a soluções com ácidos orgânicos. O sistema radicular na fase inicial de crescimento vegetal é a estrutura mais afetada, refletindo na sua massa seca de raízes, que, de acordo com KOPP et al. (2007b), esse efeito fitotóxico é dependente do comprimento da cadeia de carbonos e concentração desses ácidos.

A presença de ácidos orgânicos no solo dificulta o estabelecimento do estande inicial de plântulas de arroz, pois é um dos fatores ambientais que podem prejudicar a germinação e a viabilidade das sementes. Pelos resultados da figura 1A, verificase que o ácido acético provoca redução na germinação a partir da dose de $8 \mathrm{mM}$, com uma média acima de $85 \%$, enquanto o ácido butírico causa problemas a partir da dose de $4 \mathrm{mM}$. Dessa forma, a porcentagem de germinação ideal para comercialização de sementes de arroz no Estado do Rio Grande do Sul foi afetada apenas a partir da dose de $12 \mathrm{mM}$. No entanto, para o ácido propiônico, a dose de $16 \mathrm{mM}$ é que foi 


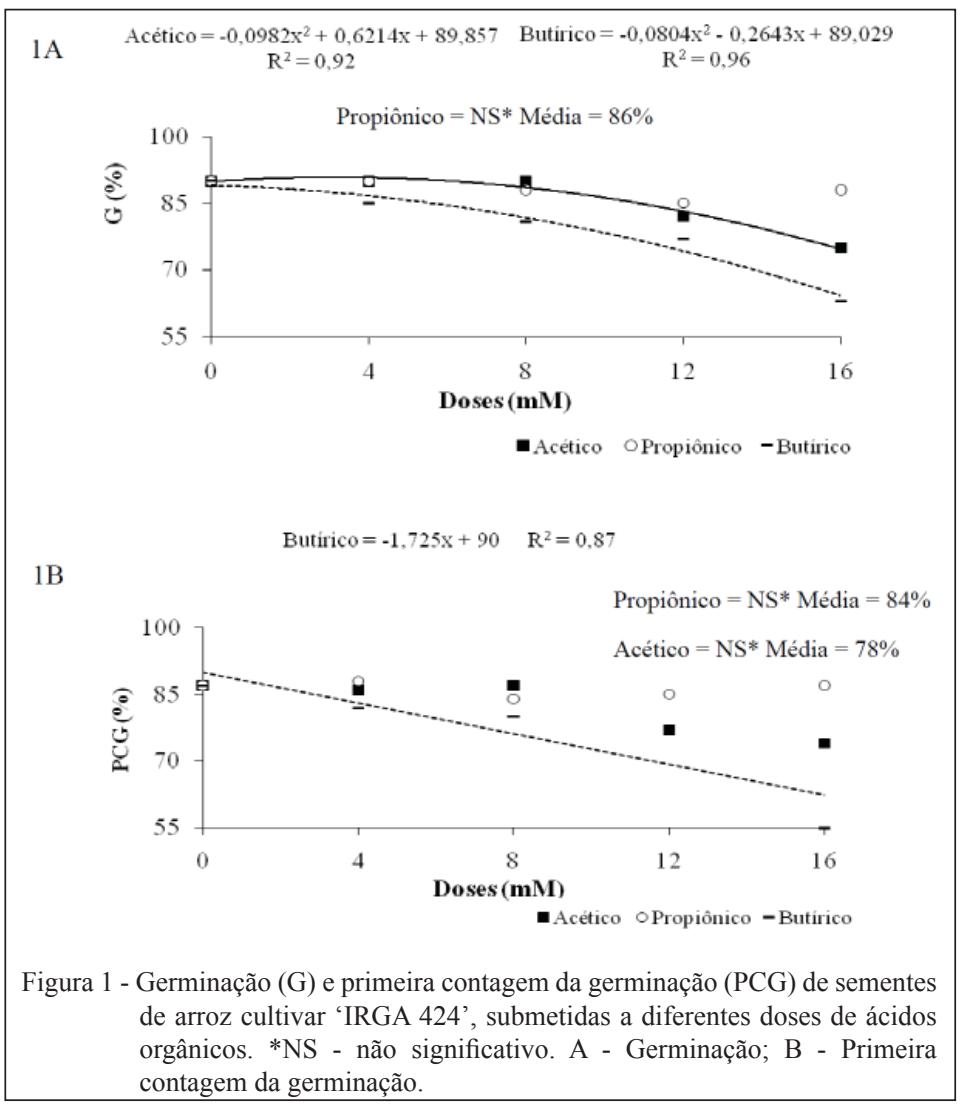

prejudicial na porcentagem de germinação para o processo de comercialização, ou seja, abaixo de $80 \%$.

Nas sementes de arroz, os ácidos orgânicos causam a degradação das membranas celulares e perda do conteúdo celular para o meio (KOPP et al., 2007b), mas também cultivares tolerantes devem possuir genes que conferem maior capacidade de formação de membranas celulares que tolerem esses ácidos (ARMSTRONG \& ARMSTRONG, 2001). As sementes da cultivar 'IRGA 424' são de elevada capacidade germinativa, podendo ser consideradas insensíveis à toxicidade, devido à maior capacidade de manutenção celular em condição de estresse, causados pelos ácidos acético e butírico, nas concentrações inferiores a $8 \mathrm{mM}$ (Figura 1A).

As doses de 12 e $16 \mathrm{mM}$ dos ácidos acético e butírico ocasionaram uma diminuição na porcentagem de germinação das sementes de arroz de 9 e $14 \%$ e de 17 e $30 \%$, respectivamente, quando comparadas às sementes da testemunha (Figura 1A). Segundo NEVES et al. (2010), a toxidez por ácidos orgânicos manifesta-se nas fases iniciais de desenvolvimento das plântulas de arroz, pela menor germinação, sendo que, em casos de toxidez mais severa, como ocorreu nas doses de 12 e $16 \mathrm{mM}$ dos ácidos acético e butírico, os prejuízos ao crescimento e desenvolvimento podem se refletir em outras fases, ocorrendo menor rendimento de grãos (CAMARGO et al., 2001). A maior produção de ácidos orgânicos ocorre na fase inicial de semeadura, segundo KOPP et al. (2008), é onde os efeitos estão mais relacionados à fase de germinação, por isso, a maior preocupação está voltada para o estabelecimento das plântulas de arroz na fase inicial de desenvolvimento.

Pelos dados da primeira contagem de germinação das sementes de arroz (Figura 1B), observa-se que o ácido butírico reduziu a porcentagem de plântulas normais de forma linear, à medida que ocorreu o aumento das doses, reduzindo significamente o vigor das sementes. $\mathrm{Na}$ dose de $16 \mathrm{mM}$, houve redução de $37 \%$ na germinação, quando comparada à dose de $0 \mathrm{mM}$. Resultados semelhantes foram obtidos por TUNES et al. (2008) em sementes de em cevada, trigo e aveia. No entanto, os ácidos acético e propiônico não influenciaram nos resultados da primeira contagem da germinação (Figura 1B), que é considerado um teste de vigor, o qual, segundo NEVES et al. (2007), é indispensável para avaliar os efeitos desses ácidos nas sementes, juntamente com testes de germinação e de viabilidade. 
Com relação ao comprimento da parte aérea, também foi verificada resposta diferenciada das plântulas de arroz frente aos ácidos analisados (Figura 2A). Para os três ácidos, ocorreu uma redução linear, à medida que se aumentou a concentração deles nas sementes, com uma redução de 67,40 e $24 \%$ no comprimento da parte aérea das plântulas oriundas de sementes embebidas com ácido butírico, acético e propiônico na dose de $16 \mathrm{mM}$, respectivamente, quando comparadas àquelas originadas de sementes da testemunha.

Assim, pode-se verificar que doses elevadas de ácidos orgânicos prejudicaram a qualidade fisiológica de sementes de arroz da cultivar
'IRGA 424', conforme dados anteriores. Os ácidos butírico e acético são os que têm maior concentração no solo e predominam por mais tempo, de forma que SCHMIDT et al. (2007) relataram que observar o comportamento das sementes frente a esses ácidos é essencial para analisar a sua capacidade de tolerância. O comprimento das raízes de arroz diminuiu sensivelmente com as doses crescentes de ácido acético (Figura 2B), com uma redução de $50 \%$ na dose mais elevada $(16 \mathrm{mM})$, comparada à testemunha, sendo essa variável considerada a mais afetada frente ao estresse por ácidos orgânicos. No entanto, nas pesquisas de TAKIJIMA (1964) e NEVES et al. (2010), foi verificada uma redução de

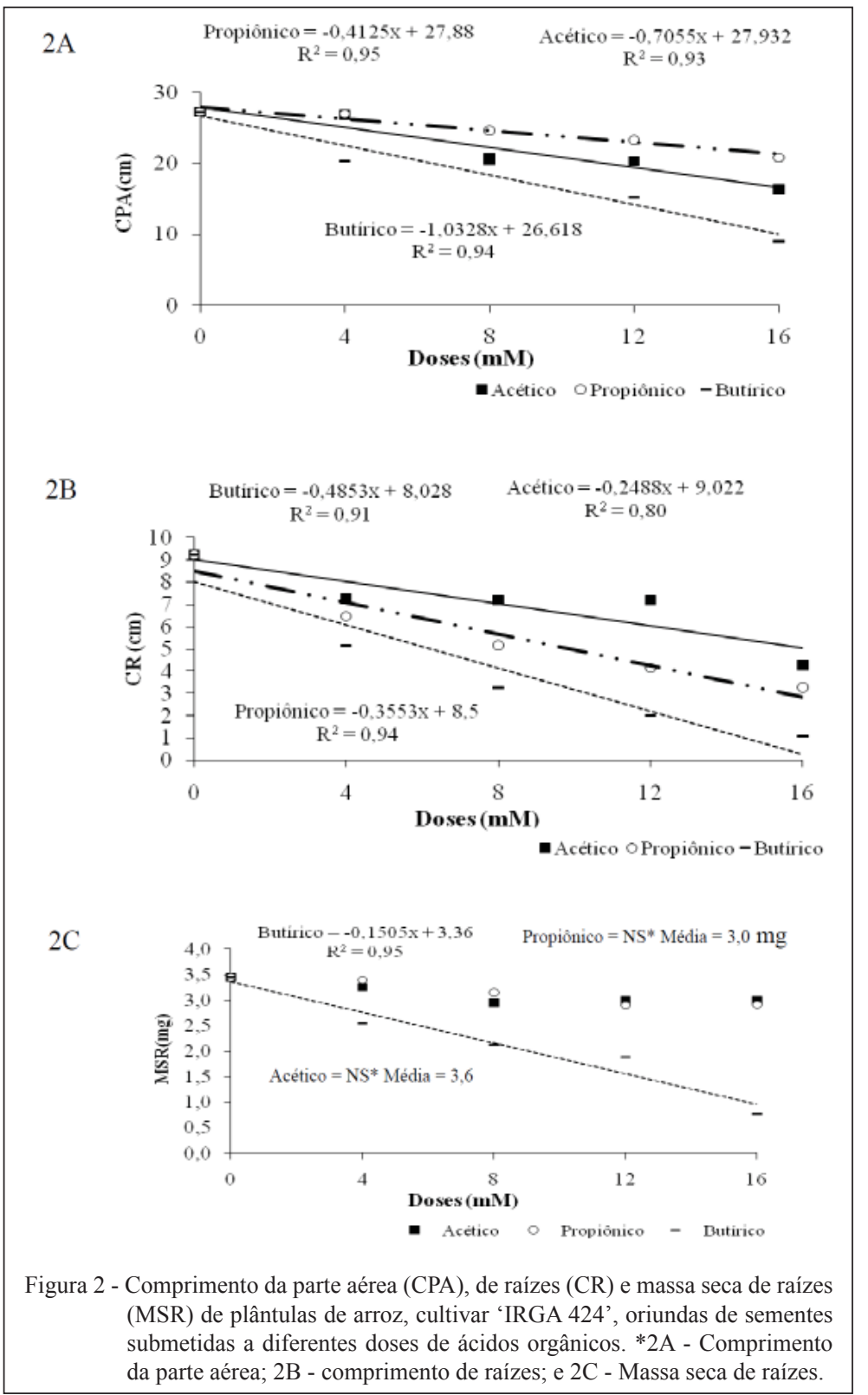

Ciência Rural, v.43, n.7, jul, 2013. 
$50 \%$ no crescimento de raízes de plântulas de arroz na dose de 5,0 e 13,6mM, respectivamente. SOUZA $\&$ BORTOLON (2002) verificaram que, para reduzir $50 \%$ do crescimento do sistema radicular da soja, a concentração de ácido acético foi de $2,0 \mathrm{mM}$ e, para o sorgo, foi de $1,8 \mathrm{mM}$. Os mesmos pesquisadores observaram que uma inibição de $50 \%$ no crescimento do sistema radicular de plantas de arroz foi obtida a uma concentração de $4,7 \mathrm{mM}$, enquanto que, na parte aérea, para atingir o mesmo valor de inibição, foi necessária uma concentração de $8,0 \mathrm{mM}$ de ácido acético. Os ácidos monocarboxílicos como o acético alteram a composição dos ácidos orgânicos na membrana plasmática, promovendo um decréscimo da proporção dos ácidos polisaturados, afetando propriedades importantes da membrana, como a seletividade, aumentando o extravasamento de solutos e ocasionando redução de sua expansão celular.

Para o ácido propiônico, houve um decréscimo linear no comprimento das raízes (Figura 2B), em que a dose de $12 \mathrm{mM}$ provocou uma redução de $50 \%$ do crescimento radicular, quando comparado à testemunha. No entanto, a dose de $4 \mathrm{mM}$ do ácido butírico foi suficiente para gerar uma diminuição brusca de 50\% no crescimento radicular das plântulas de arroz. Pelos dados obtidos, constata-se que o ácido acético foi menos tóxico, seguido do propionico e butírico. Para a massa seca de raízes (Figura 2C), os valores foram significativos para o ácido butírico, cuja redução foi linear, ou seja, na dose mais elevada $(16 \mathrm{mM})$, diminuição de $65 \%$, quando comparada à testemunha.

Os sintomas fisiológicos relacionados à toxidez dos ácidos orgânicos em sementes de arroz estão relacionados à degradação da parede celular, inibição de funções respiratórias e, consequentemente, diminuição da divisão celular do sistema radicular. Essa redução, segundo pesquisa de ARMSTRONG \& ARMSTRONG (2001), se dá por que o sistema radicular fica em contato direto com os ácidos butírico, acético e propiônico, ocasionando, assim, fitotoxicidade, a razão principal para o menor crescimento radicular e acúmulo de massa seca.

\section{CONCLUSÃO}

$\mathrm{Na}$ avaliação da qualidade das sementes frente ao estresse por ácidos orgânicos, o comprimento das raízes foi mais eficiente para diferenciar a toxicidade nas doses de ácido acético, butírico e propiônico. O ácido butírico foi o mais prejudicial para sementes de arroz, afetando o desenvolvimento inicial das plântulas da cultivar 'IRGA 424'.

\section{REFERÊNCIAS}

ARMSTRONG, J.; ARMSTRONG, W. Rice and Phragmites: effects of organic acids on growth, root permeability, and radial oxygen loss to the rhizosphere. American Journal of Botany, v.88, n.8, p.1359-1370, 2001.

ANGELES, O.R. et al. Soil solution sampling for organic acids in rice paddy soils. Soil Society American Journal, v.70, n.1, p.48-70, 2005.

BOHNEN, H. et al. Ácidos orgânicos na solução de um gleissolo sob diferentes sistemas de cultivo com arroz irrigado. Revista Brasileira de Ciência do Solo, v.29, n.2, p.475-480, 2005

BORTOLON, L. et al. Toxidez por ácidos orgânicos em genótipos de arroz irrigado. Scientia Agraria, v.10, n.1, p.81-84, 2009.

BRASIL. Ministério da Agricultura, Pecuária e Abastecimento. Regras para análise de sementes. Secretaria de Defesa Agropecuária. Brasília: MAPA/ACS, 2009. 395p.

CAMARGO, F.A.O. et al. Incorporação de palha de arroz em um gleissolo e efeitos no rendimento da cultura do arroz irrigado. Pesquisa Agropecuária Brasileira, v.30, n.7, p.983-987, 1993.

CAMARGO, F.A. et al. Aspectos fisiológicos e caracterização de toxidez a ácidos orgânicos voláteis em plantas. Ciência Rural, v.31, n.3, p.523-529, 2001.

FERREIRA, D.F. Análises estatísticas por meio do SISVAR para Windows versão 4.0. In: REUNIÃO ANUAL DA REGIÃO BRASILEIRA DA SOCIEDADE INTERNACIONAL DE BIOMETRIA, 45., 2000, São Carlos, SP. Anais... São Carlos: UFSCAR, 2000. p.225-258.

IRGA (INSTITUTO RIO-GRANDENSE DO ARROZ). Dados da safra. Ano 2011. Disponível em: <http://www.irga.rs.gov.br/ index.php?action=noticia_detalhe $\& i d=3437>$. Acesso em: $20 \mathrm{dez}$. 2011

KOPP, M.M. et al. Níveis críticos dos ácidos acético, propiônico e butírico para estudos de toxicidade em arroz em solução nutritiva. Acta Botanica Brasilica, v.21, n.1, p.147-154, 2007a. Disponível em: $<$ http://www.scielo.br/pdf/abb/v21n1/14.pdf $>$. Acesso em: 01 dez. 2011.

KOPP, M.M. et al. Organic acid tolerance in $M_{3}$ families of oat mutants. Crop Breeding and Applied Biotechnology, v.7, n.1, p.59-66, 2007b

KOPP, M.M. et al. Análise da germinação de cultivares de arroz submetidas a estresse por ácido acético. Ciência Rural, v.38, n.9, p.2599-2603, 2008.

KRYZANOWSKI, F.C. et al. Vigor de sementes: conceitos e testes. Londrina: ABRATES, 1999. Cap.6.1, p.6-8.

NEVES, L.A.S.; MORAES, D.M. Análise do vigor e da atividade da $\alpha$-amilase em sementes de cultivares de arroz submetidas a diferentes tratamentos com ácido acético. Revista de Ciências Agroveterinárias, v.4, n.1, p.35-43, 2005.

NEVES, L.A.S. et al. Vigor de sementes e atividade bioquímica em plantas de arroz submetidas a ácidos orgânicos. Pesquisa Agropecuária Gaúcha, v.1, n.13, p.79-80, 2007. 
NEVES, L.A.S. et al. Qualidade fisiológica de sementes de arroz irrigado submetidas a ácidos orgânicos. Revista de Ciências Agroveterinárias, v.9, n.2, p.169-177, 2010.

SCHMIDT, F. et al. Toxidez pelos ácidos propiônico e butírico em plântulas de arroz. Ciência Rural, v.37, n.3, p.720-726, 2007.

SCHMIDT, F. et al. Nível crítico de toxidez do ácido acético em culturas alternativas para solos de várzea. Ciência Rural, v.40, n.5, p.1068-1074, 2010. Disponível em: <http:/www.scielo.br/ pdf/cr/v40n5/a591cr1057.pdf $>$. Acesso em: 01 dez. 2011. doi: 10.1590/S0103-84782010005000083.

SOUSA, R.O.; BORTOLON, L. Crescimento radicular e da parte aérea do arroz (Oryza sativa L.) e absorção de nutrientes em solução nutritiva com diferentes concentrações de ácido acético. Revista Brasileira de Agrociência, v.8, n.3, p.231-235, 2002.
SOUSA, R.O.; BORTOLON, L. Crescimento radicular e da parte aérea do arroz (Oryza sativa L.) e absorção de nutrientes em solução nutritiva com diferentes concentrações de ácido acético. Revista Brasileira de Agrociência, v.8, n.1, p.231-235, 2006.

TAKENAGA, H. Nutrient absorption in relation to environmental factors. In: MATSUO, T. et al. Science of the rice plant: physiology. Tokyo: Nosan Gyoson Bunka Kyokai, 1995. p.278294.

TAKIJIMA, Y. Growth inhibiting action of organic acids and absorption and decomposition of them by soils. Soil Science Plant Nutrition, v.12, n.4, p.435-442, 1964.

TUNES, L.M. et al. Aspectos fisiológicos da toxidez de ácidos orgânicos em sementes de aveia. Biotemas, v.21, n.4, p.21-28, 2008 . 